\title{
CAZADORES RECOLECTORES DEL PERIODO ARCAICO EN LOS VALLES Y SERRANÍAS DE LA REGIÓN DE SAN LUCAS, CHUQUISACA, BOLIVIA*
}

\author{
HUNTER GATHERERS OF THE ARCHAIC PERIOD IN THE VALLEYS \\ AND MOUNTAINS OF SAN LUCAS, CHUQUISACA, BOLIVIA
}

\author{
Claudia Rivera Casanovas ${ }^{1}$ y Sergio Calla Maldonado ${ }^{2}$
}

\begin{abstract}
La arqueología del período Arcaico en Bolivia se ha centrado principalmente en las tierras altas del Altiplano. Sin embargo, nuevos estudios en regiones de valles y tierras bajas muestran la presencia de poblaciones arcaicas no conocidas previamente. En este trabajo presentamos los resultados obtenidos a partir de una prospección regional en la región de San Lucas, sur de Bolivia. Se exploran las características de los patrones de asentamiento, la tecnología a partir del análisis de los conjuntos artefactuales y se plantea una cronología preliminar para las ocupaciones arcaicas en esta región.
\end{abstract}

Palabras claves: cazadores recolectores, patrones de asentamiento, tecnología lítica, San Lucas, Chuquisaca, Bolivia.

The archaeology of the Archaic Period in Bolivia has primarily been studied in the central and southern highlands. However, new studies in diverse areas of the valleys and lowlands have demonstrated the existence of important Archaic populations previously unknown. In this paper we present the results obtained through a regional survey in the region of San Lucas, southern Bolivia. We explore the characteristics of the settlement patterns, the technology based on an analysis of lithic assemblages, and we outline a preliminary chronology for the Archaic occupations in this region.

Key words: Hunter gatherers, settlement patterns, lithic technology, San Lucas, Chuquisaca, Bolivia.

El estudio de las sociedades tempranas de cazadores recolectores ha sido un tema de amplio interés en la arqueología andina. Distintos acercamientos a esta problemática tuvieron, durante gran parte del siglo XX, un carácter exploratorio (identificación y descripción de sitios y artefactos) y un fuerte énfasis en el establecimiento de tipologías de materiales líticos (Lanata y Borrero 1999).

Esta visión fue cambiando desde los años 60 del siglo pasado gracias al desarrollo de investigaciones más sistemáticas y excavaciones detalladas que permitieron indagar sobre una diversidad de temas tales como patrones de trashumancia, movilidad estacional, explotación de recursos y adaptación a diversos medios y variación paleoclimática, entre muchos otros (p.ej., Aldenderfer 1989; Núñez et al. 2005; Núñez y Santoro 1988; Rick 1988). Dentro de nuevas perspectivas que consideran aspectos adaptativos y de cambio cultural resalta el importante trabajo de Mark Aldenderfer y colegas en la cuenca alta del río Osmore, Moquegua, y más recientemente en la región del río Ilave en la cuenca del Titicaca (Aldenderfer 1998; Klink y Aldenderfer 2005).

No obstante los avances logrados en la investigación de estos períodos tempranos, algunas de las limitaciones que han persistido en muchos estudios se relacionan con trabajos enfocados en muy pocos sitios arqueológicos y la falta de una visión regional que permita explorar la estructura de las sociedades cazadoras recolectoras, sus patrones de movilidad y la variabilidad que dejaron en el registro arqueológico producto de estrategias de ocupación del espacio, la explotación de recursos y las actividades diversas realizadas en él.

Sin duda los estudios de patrones de asentamiento regionales han contribuido en gran medida, en las

\footnotetext{
* Un texto preliminar de este artículo fue presentado en el $53^{\circ}$ Congreso Internacional de Americanistas, Simposio "El período Arcaico en los Andes Sur Centrales: Tradiciones culturales e innovaciones tecnológicas", Ciudad de México, 19 al 24 de julio de 2009. Este manuscrito fue seleccionado para ser evaluado por investigadores externos y editado por Luis Flores Blanco y Mark S. Aldenderfer, en su calidad de editores invitados de la Revista.

1 Instituto de Investigaciones Antropológicas y Arqueológicas, Carrera de Arqueología, Universidad Mayor de San Andrés, La Paz-Bolivia. clauri68@yahoo.com

2 Carrera de Arqueología, Universidad Mayor de San Andrés, La Paz-Bolivia.
} 
últimas dos décadas, a ampliar nuestro entendimiento sobre las sociedades tempranas y sus características a nivel regional. Este tipo de investigaciones permite contar con una muestra representativa de distintos tipos de asentamientos y rasgos arqueológicos dejados en el paisaje, lo que hace posible una aproximación más comprensiva a los sistemas de asentamiento a las estrategias adaptativas y de movilidad, además de ciertos aspectos simbólicos de estas sociedades.

Los estudios sobre el período Arcaico en Bolivia son hasta ahora bastante limitados, centrados en pocos sitios arqueológicos y, con muy pocas excepciones, no consideran un enfoque regional amplio. La carencia de estudios de naturaleza regional ha dificultado la comprensión de este período temprano.

El trabajo de prospección arqueológica realizado el 2006 en la región de San Lucas, Chuquisaca, tuvo un enfoque regional que permitió una aproximación más integral a la arqueología de los períodos tempranos. Entre sus objetivos estuvo el generar información regional para realizar un estudio diacrónico sobre los patrones de asentamiento prehispánicos y sus cambios en el tiempo. Este estudio ha producido una importante cantidad de datos sobre las ocupaciones humanas del período Arcaico que permite explorar, por primera vez, los patrones de asentamiento, las estrategias adaptativas y aspectos simbólicos de las primeras sociedades que habitaron los valles interandinos del sur de Bolivia.

\section{Investigaciones sobre el Período Arcaico en Bolivia}

En Bolivia, el estudio de las sociedades arcaicas ha seguido las características mencionadas arriba para los Andes centrales y sur centrales en cuanto a estudios exploratorios, establecimiento de tipologías y visiones difusionistas (p.ej., Arellano 1992, 2000; Ibarra Grasso 1973). No obstante, este período ha pasado casi desapercibido dentro de la investigación arqueológica por el fuerte énfasis que existe en el estudio de sociedades complejas más tardías. Algunos temas recurrentes han estado enfocados en entender la naturaleza de las sociedades sedentarias tempranas, el desarrollo estructuras políticas complejas y la exploración de trayectorias evolutivas locales y el desarrollo de sociedades diversas.

El estudio del período Arcaico en Bolivia ha sido abordado de manera asistemática $\mathrm{y}$, salvo por contadas excepciones, responde a hallazgos fortuitos dentro de investigaciones enfocadas en otras problemáticas. Se tienen datos de sitios arcaicos localizados tanto en el altiplano como en los valles de Bolivia y en algunos casos se cuenta con fechados radiocarbónicos (Albarracin-Jordan 1996:93; Brockington et al. 1986; Céspedes Paz 2002; Ibarra Grasso 1973; Rivera Casanovas et al. 2007; Stanish 2003). Estos datos indican una importante ocupación arcaica en distintas regiones del altiplano y los valles que amerita ser estudiada en detalle (Figura 1).

En las tierras altas dos regiones concentraron la atención de la comunidad científica durante el siglo pasado: la del Altiplano de Lípez (Potosí), principalmente por los trabajos de Arellano (2000), a los que se suman los estudios de Albarracin-Jordan y Michel López (1998), Berberián y Arellano (1977) y Barfield (1961); y la de Viscachani (La Paz), con los trabajos de Ibarra Grasso (1965, 1973), Ibarra Grasso y Querejazu Lewis (1986), Kornfield (1975), Patterson y Heizer (1965) y Lizárraga-Mehringer (2004). Actualmente se realizan investigaciones regionales en el altiplano central en las regiones de los ríos Mauri (Jiménez 2007) y Desaguadero (Irahola 2007), enfocadas en entender los patrones de ocupación arcaicos.

En los valles del norte y centro de Bolivia los trabajos son más escuetos. Existen evidencias sobre ocupaciones arcaicas no bien estudiadas en sitios del valle de La Paz como Pampajasi y Chullpani (Lémuz Aguirre y Aranda Álvarez 2008). En los valles de Cochabamba se conoce una serie de sitios como Kayarani, Vila Vila y Viloma, aunque no han sido publicados en detalle (Céspedes Paz 2002). Los trabajos en la cuenca de Misicuni (3.750 msm) revelaron la existencia de abrigos rocosos con ocupaciones pertenecientes al Arcaico Tardío asociadas $\mathrm{a}$ áreas de bofedales, cuyos materiales diagnósticos son puntas de proyectil foliáceas con bases romas y pedunculadas, además de cuchillos, preformas y lascas (Céspedes Paz 2002). En Mayra Pampa, Mizque, se encontraron contextos arcaicos con fogones y artefactos líticos (lascas y raspadores) bajo ocupaciones formativas. Estos contextos fueron fechados hacia el 2.500 a.C., es decir, el Arcaico Tardío (Brockington et al. 1995).

Investigaciones regionales en los valles de Santa Cruz, en la región de La Laja, Vallegrande, identificaron tres sitios probablemente pertenecientes al período Arcaico (Rivera Casanovas et al. 2007). Estos sitios presentaron núcleos y raspadores 


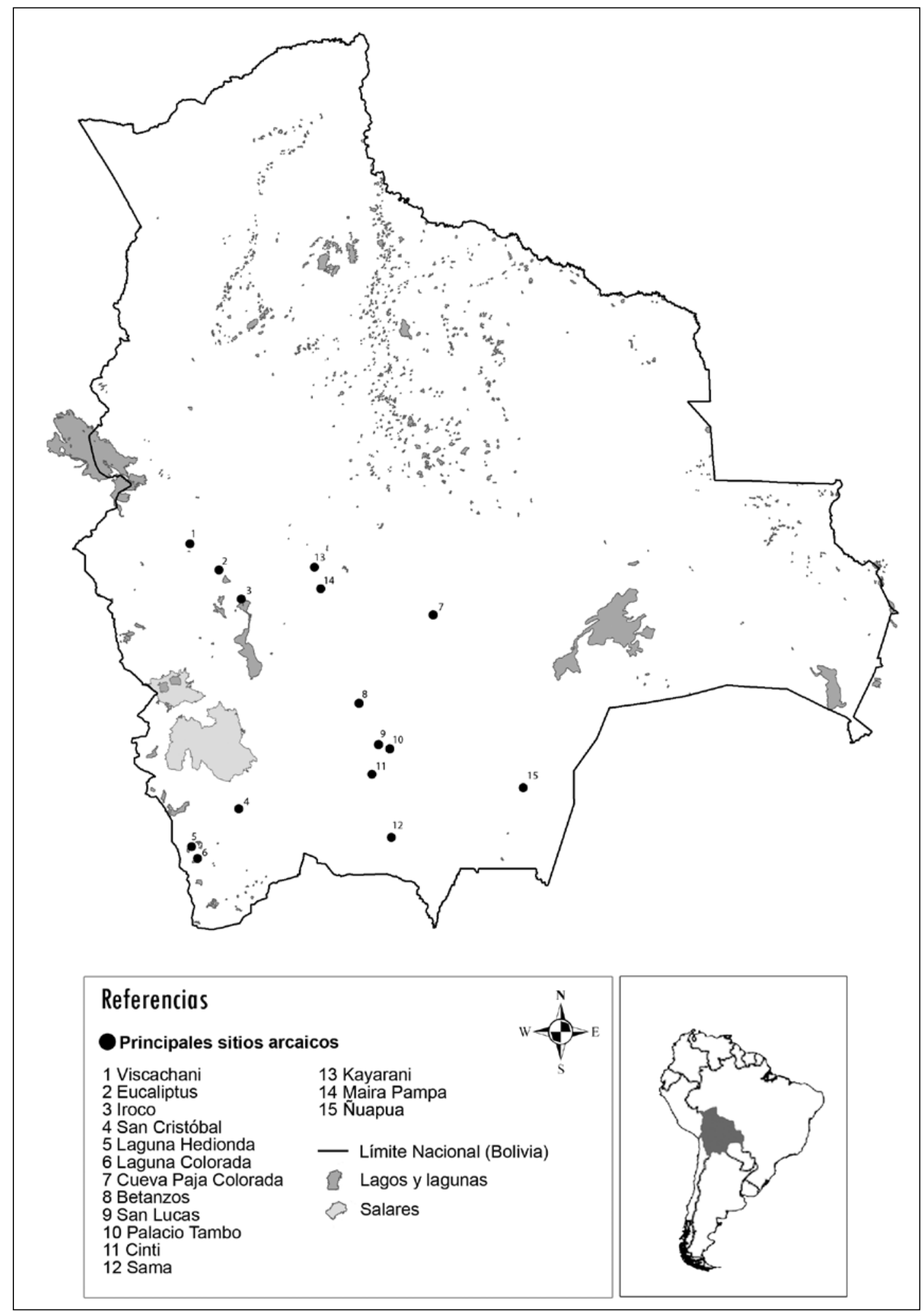

Figura 1. Sitios arqueológicos del período Arcaico en Bolivia.

Archaic Period archaeological sites in Bolivia. 
morfológicamente similares a artefactos del período Arcaico en Cochabamba. Además, existe una cueva con pinturas rupestres con representaciones de manos en negativo que podrían asociarse a este período, aunque estratigráficamente esto no ha podido ser corroborado.

Otro sitio de gran interés es Nuapua, situado en el Chaco boliviano, donde se encontraron restos humanos asociados a artefactos líticos y megafauna, datado en el 6.600 a.p. (Arellano 1986).

\section{Paleoclima}

La historia paleoclimática en las últimas décadas ha provisto importantes datos para la reconstrucción del clima global y su variabilidad en el pasado. Numerosas investigaciones se concentraron en el Altiplano Andino (Cordillera Occidental) y en la Cordillera Este, identificando una serie de eventos y oscilaciones ocurridos durante el Pleistoceno y el Holoceno para la cuenca del lago Titicaca (Abbott et al. 1997; Abbott et al. 2003; Ahlfeld y Braniĉa 1960; Argollo y Mourguriat 1995, 2000; Baker et al. 2001; Binford et al. 1997; Blard et al. 2009; Levenu et al. 1984; Placzek et al. 2006; Placzek et al. 2009; Rigsby et al. 2005; Servant y Servant-Vildary 2003). Estos estudios reconocen la existencia de paleolagos en el Altiplano que tuvieron una fuerte influencia en el paleoclima y han documentado sus distintas fases lacustres en detalle. También se ha resaltado la influencia que tuvieron los regímenes climáticos amazónicos para la expansión de los paleolagos bolivianos (Placzek et al. 2006).

Para la Cordillera Este (Cordilleras Oriental, de Apolobamba y de Quimsa Cruz), que tiene características geomorfológicas y paleoclimáticas distintas a las de la Cordillera Occidental por bordear la Cuenca Amazónica, los estudios demuestran la importancia de la estacionalidad del clima en la antigüedad (Kull et al. 2008). Las precipitaciones de verano fueron la fuente de humedad en el pasado, al igual que hoy en día. El escenario para el 20.000 a.p. indica un avance de los paleoglaciales en la Cordillera Este, mientras que para el 14.000 a.p. la humedad del final de la glaciación produjo glaciaciones de geometría diferente (Kull et al. 2008). Los pocos estudios sobre la evolución paleoambiental y geomorfológica de la zona este boliviana sugieren que esta tuvo características particulares y efectos en el paleoclima por los regímenes semiáridos del
Chaco y el clima tropical amazónico (May et al. 2008).

Las reconstrucciones paleoambientales para el Holoceno, durante el 12.000-10.000 a.p., indican que en la Cordillera Boliviana existieron una serie de fluctuaciones climáticas que favorecieron el derretimiento de los glaciales y generaron mejores condiciones para habitar la región (Abbott et al. 1997; Seltzer 1992). La mejora de las condiciones climáticas durante el Holoceno fue un factor importante en las zonas altas y el piso prepuneño, para la adaptación humana y los desarrollos culturales. Esta situación también benefició a los valles interandinos del sureste boliviano, con altitudes entre los 2.100 y $3.200 \mathrm{msm}$, que experimentaron los efectos de las condiciones paleoclimáticas del Chaco y la Amazonia que probablemente tuvieron una influencia directa en el comportamiento paleoclimático, favoreciendo las condiciones para la ocupación humana en estas regiones (Kull et al. 2008; May et al. 2008).

\section{El Período Arcaico en los Valles del Sur de Bolivia}

Los valles del sur de Bolivia se sitúan al sur de los $19^{\circ} \mathrm{S}$. Están caracterizados como ambientes semiáridos por la baja cantidad de lluvia que reciben, alrededor de $500 \mathrm{~mm}$ anuales, por la presencia de vegetación xerofítica y por un clima árido y semiárido según el método Thornthwaite (ZONISIG 2000:37). Estos valles se intercalan con cordones montañosos dando lugar a un paisaje altamente disectado con diferencias altitudinales marcadas.

El período Arcaico en los valles del sur de Bolivia es poco conocido aunque la presencia de grupos de cazadores recolectores en ellos ha sido descrita en varios trabajos. Estos sugieren una larga e importante ocupación en diversas regiones, relacionada con la caza de camélidos, cérvidos y otros animales. Por ejemplo, para la región sudeste de Potosí, Lecoq y Céspedes (1997:33) señalan la presencia de cuatro sitios precerámicos en cuevas y aleros rocosos de la cuenca del río Yura. Estos sitios muestran pinturas rupestres bien conservadas que podrían datar de este período, además de conjuntos líticos compuestos por puntas de proyectil foliáceas, raspadores bifaciales, núcleos y esquirlas de cuarcita y sílex.

Más recientemente, Rivera Casanovas y Calla Maldonado (2011) realizaron una prospección 
sistemática limitada, en un área de $30 \mathrm{~km}^{2}$, en los alrededores de Betanzos, una región de valles en Potosí. Identificaron 18 sitios arqueológicos, de un total de 27, con componentes del período Arcaico. En la región existieron al menos cuatro agrupamientos compuestos por sitios a cielo abierto con cantidades importantes de artefactos líticos, cuevas y aleros con arte rupestre en los que existen escenas de caza de camélidos y cérvidos, así como filas de estos animales en miniatura. Una tipología preliminar de puntas de proyectil identificó componentes correspondientes al Arcaico Temprano y Tardío.

En el cordón montañoso de Sama en Tarija, en lo que se conoce como la altiplanicie de Sama, se identificaron una serie de sitios tempranos arcaicos principalmente en las orillas de las lagunas de Tajzara y Pujzara (Michel López et al. 2000). Entre los artefactos líticos encontrados destacan puntas de proyectil foliáceas de gran tamaño, similares a las de la tradición Ayampitín en Argentina, así como raspadores, buriles, hachas de mano y otras herramientas. También se registraron manos de moler, así como restos de montículos y amontonamientos de piedra encima de enterramientos humanos (Michel López et al. [2005] 2007).

Como se mencionó, uno de los problemas principales en la investigación de las ocupaciones arcaicas en Bolivia es la naturaleza oportunista y poco sistemática de la obtención de datos. Esta situación es crítica debido a que no permite el estudio detallado de los patrones de asentamiento, el establecimiento de tipologías regionales de artefactos líticos, ni la investigación de la utilización de recursos, aspectos básicos para entender la naturaleza de estas sociedades tempranas (Aldenderfer 1989).

En este contexto, los recientes estudios regionales sistemáticos en Cinti, Chuquisaca y más específicamente en la región de San Lucas (Rivera Casanovas 2004, 2009a), brindan una oportunidad única para una primera aproximación a las ocupaciones más tempranas en esta región.

En el valle de Cinti una prospección regional sistemática documentó 12 sitios arcaicos en su parte alta, en una zona de transición de valle a prepuna (2.900-3.460 msm) (Rivera Casanovas 2004). Estos sitios estaban compuestos por cuevas, abrigos rocosos, sitios al aire libre con pequeñas estructuras circulares de un metro de diámetro (posibles refugios) y áreas de caza con dispersión de artefactos líticos como puntas de proyectil. Los artefactos diagnósticos consisten en puntas de proyectil triangulares alargadas, ojivales, triangulares con pedúnculo y una serie de bifaces, raspadores laterales y terminales. Seis de estos sitios presentaron también componentes formativos mostrando una continuidad en los patrones de subsistencia.

En la parte baja del valle, conocida como el cañón de Cinti, se registraron cuatro sitios arcaicos, uno en la base del valle y tres en una meseta alta del cerro Tonka Bajo (Rivera Casanovas 2004; Rivera Casanovas et al. 1993). Estos sitios al aire abierto presentaron concentraciones de artefactos líticos, entre los cuales destacaban puntas de proyectil triangulares alargadas y ojivales. Las características de las puntas de proyectil sugieren su pertenencia al Arcaico Medio y Tardío.

Varias de las cuevas y aleros investigados presentaron arte rupestre, generalmente figuras de camélidos y otros animales, así como motivos geométricos y antropomorfos. Trabajos posteriores en el valle alto (Rivera Casanovas 2009b) identificaron nuevas cuevas con arte rupestre que muestran figuras pequeñas de camélidos y otros animales pintadas en rojo. Este tipo de representaciones es consistente con las de otros sitios en los Andes centro sur durante el período Arcaico (p.ej., Klarich y Aldenderfer 2001).

Es probable que los grupos arcaicos en el valle de Cinti hayan tenido circuitos de movilidad estacional entre el valle y las serranías adyacentes para aprovechar los recursos de caza como camélidos, cérvidos y roedores, las fuentes de materia prima, especialmente cuarcita y pedernal, así como la recolección de frutos silvestres como el algarrobo, palqui y chañar (Rivera Casanovas 2002).

\section{La Región de San Lucas}

La región de San Lucas se encuentra en la Provincia Nor Cinti del Departamento de Chuquisaca (Figura 2), que fisiográficamente corresponde a los valles subandinos o puna desgarrada (Muñoz Reyes 1980). Geográficamente se caracteriza por la presencia de cabeceras de valle $(2.900-3.200 \mathrm{msm})$, altiplanicies (3.200-3.600 msm) y cordones montañosos altos (3.600-4.000 msm), lo cual hace posible la existencia de distintos microambientes. El valle de San Lucas corresponde a la cabecera de valle mientras que el área de Palacio Tambo corresponde a la altiplanicie.

Dentro la región de estudio, diferentes formaciones y unidades geológicas están presentes, 

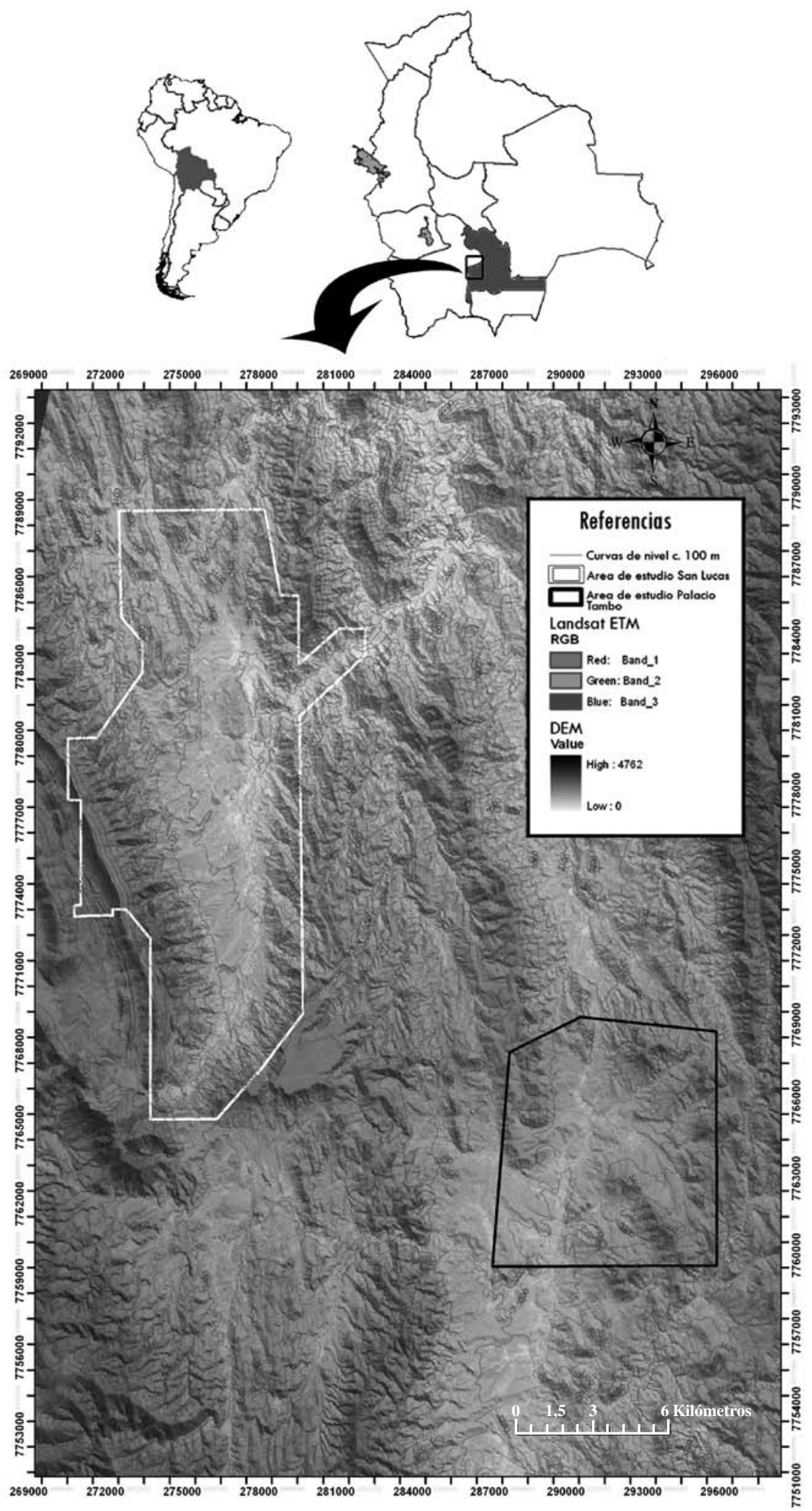

Figura 2. Región de San Lucas, Chuquisaca.

The San Lucas region, Chuquisaca. 
conformadas principalmente por rocas sedimentarias como: areniscas, lutitas, limonitas, margas, calizas y arcillitas. También el cuarzo y diversos tipos de cuarcita son comunes (Troëng et al. 1996). Las formaciones geológicas más antiguas corresponden al período Ordovícico y a la unidad geológica de rocas sedimentarias del Ordovícico. Esta consiste en una serie alternada de camas de arenisca, lutitas y limonitas. La región está atravesada por una extensa faja polimetálica (Troëng et al. 1996) asociada a distintas formaciones geológicas. Los tres tipos principales de depósitos metalíferos son: (1) depósitos vetiformes de antimonio-oro, zinc, plomo-plata y cobre asociados a series sedimentarias, (2) depósitos vetiformes polimetálicos, y (3) placeres aluviales de oro.

La región está caracterizada como semiárida pues recibe un promedio anual de $500 \mathrm{~mm}$ de lluvia. Las temperaturas promedio varían entre $23{ }^{\circ} \mathrm{C}$ en el verano y $12{ }^{\circ} \mathrm{C}$ en el invierno en las cabeceras de valle, mientras que las partes más altas soportan temperaturas menores. Las condiciones climáticas cambiantes dan lugar a heladas, sequías y granizo.

La región pertenece a la Provincia Biogeográfica Boliviano Tucumana, cuya vegetación se identifica como Vegetación Puneña Superior del Río San Juan del Oro, por encima de los 2.900-3.100 msm y hasta los $3.300 \mathrm{~m}$ de altitud. Se trata de un microbosque semiárido espinoso, dominado por árboles de Churqui (Prosopis ferox) y por cactáceas arbóreas endémicas Echinopsis (Trichocereus) wendermannianus, al igual que por matas y arbustos xerofíticos y numerosas cactáceas (Navarro y Maldonado 2004). También existen gramíneas y pastos de ambientes secos (ZONISIG 2000). En las partes altas de los cerros con presencia de fuentes de agua y quebradas aún existen bosques relictuales de queñua (Polilepis sp.). La vegetación xerofítica tiene una mayor presencia y densidad en el valle de San Lucas mientras que en Palacio Tambo es más escasa.

La fauna nativa ha sido en gran medida desplazada de su hábitat natural por la acción humana buscando refugio en zonas apartadas, tal es el caso de felinos como el puma (Felis concolor) y cérvidos como la taruka o venado andino (Hippocamelus antisensis). Especies comunes son los zorros, zorrillos, roedores, variedad de aves, reptiles e insectos. Los ríos de la región están poblados por especies de peces pequeños o challhuas. En el pasado la región debió estar poblada por camélidos como vicuñas y guanacos que hoy en día han desaparecido. Según relatos de ancianos, que fueron recogidos en el valle de Cinti en los años 90 del siglo pasado, hasta la primera mitad del siglo XX existían poblaciones de guanacos en las serranías de Lique y Mochará que fueron exterminadas por una caza desmedida.

\section{Microambientes}

En el valle de San Lucas se han establecido cinco microambientes considerando el relieve topográfico, la geomorfología y la vegetación (Figura 3), estos son: base de valle, piedemonte y serranía este, piedemonte oeste, colinas y quebradas y serranía alta oeste. En la zona de Palacio Tambo se definieron dos microambientes: base de la cuenca o altiplanicie y serranías altas.

\section{Base de valle (BV)}

Se caracteriza por estar a una altitud de 2.950$3.100 \mathrm{msm}$ y alcanzar su mayor extensión en el sector norte del valle mientras que se va estrechando conforme se avanza hacia el sur, formando una especie de triángulo invertido. Hacia su parte este está delimitado por el río San Lucas, presentando terrazas aluviales cortadas por éste y por otros ríos como el de Yapusiri. Los ríos de la región descienden de las serranías circundantes y se van uniendo al río San Lucas en distintos sectores de la base de valle.

Los suelos en este microambiente son aptos para la actividad agrícola, la cual ha alterado de gran manera la vegetación nativa. Sin embargo, especies comunes como el churqui aún llegan a formar áreas boscosas en lugares poco intervenidos o abandonados. En menor proporción se presentan el algarrobo, molle, una variedad de cactáceas y especies arbustivas espinosas. Esta vegetación muestra una transición entre el piso de prepuna o subpuna y el de puna, característicos del sur de Bolivia.

\section{Piedemonte y serranía este (PE)}

Este microambiente está delimitado hacia su parte oeste por el río San Lucas. Presenta áreas de piedemonte de poca extensión que, en muchos sectores, dan lugar a pendientes fuertes, mayores a $45^{\circ}$. Estas áreas dan paso a una serranía que alcanza una elevación promedio de $3.300 \mathrm{msm}$. En esta zona una serie de quebradas que corren en dirección 
440

Claudia Rivera Casanovas y Sergio Calla Maldonado
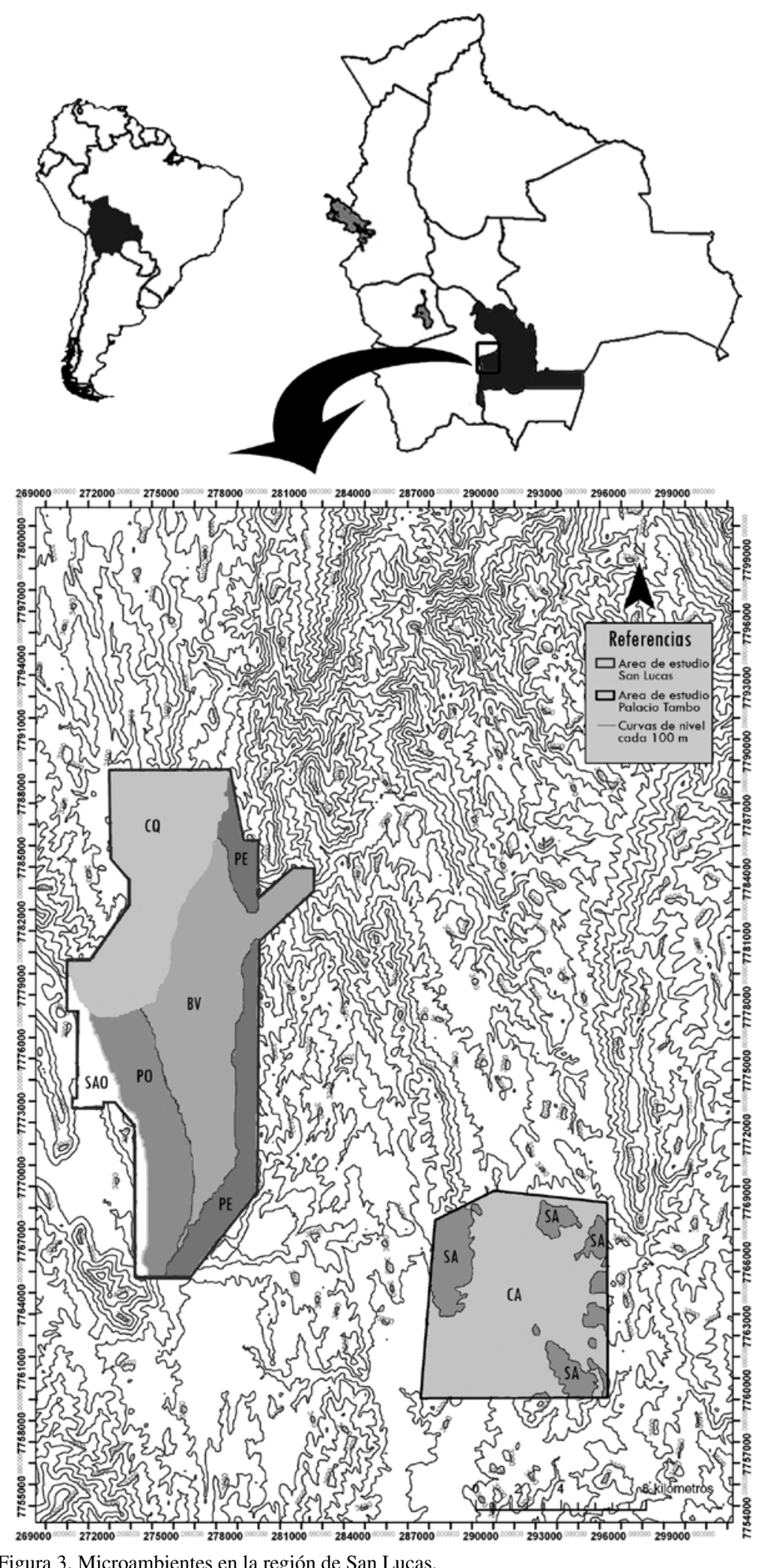

Figura 3. Microambient 
sureste-noroeste dan lugar a ríos estacionales. Existen afloramientos de cuarcita así como de minerales y cobre y otros que han sido explotados desde tiempos prehispánicos dando lugar a la existencia de varias minas. La vegetación está compuesta por arbustos xerofíticos, molle, cactáceas y gramíneas. Muchos sectores del piedemonte y la serranía fueron empleados para tareas agrícolas donde se cultivó con canales de irrigación y sistemas a secano, existiendo restos de terrazas prehispánicas y coloniales en áreas aptas y abrigadas. Sin embargo, hoy en día estas terrazas a secano han sido abandonadas por falta de agua. En el pasado los sectores de piedemonte fueron aprovechados para establecer asentamientos humanos.

\section{Piedemonte oeste (PO)}

Presenta extensiones más grandes de terreno, comparada con la serranía este. Las pendientes tienden a ser más suaves dando lugar a colinas que corren en dirección este-oeste y suroeste-noreste, cortadas por ríos y quebradas. La altitud varía entre 3.150 y $3.600 \mathrm{msm}$. En muchos lugares existen colinas que conforman mesetas bajas. Su vegetación se caracteriza por árboles de churqui y molle, cactáceas y gramíneas. Es una zona usada extensivamente hoy en día para actividades agrícolas a secano como seguramente sucedió en el pasado. Existen sectores con mucha erosión, especialmente donde el piedemonte da lugar a la base de valle.

\section{Colinas y quebradas $(C Q)$}

En la parte noroeste del valle, hacia el norte de la comunidad de Querquewisi, el paisaje cambia por las características de la cadena montañosa que se abre hacia el valle, dando lugar a una serie de pequeñas cuencas interiores y quebradas. Las que se hallan hacia el oeste siguen un rumbo suroeste-noreste y se encuentran con otras orientadas aproximadamente de norte a sur. La altitud promedio oscila entre 3.100 y $3.400 \mathrm{msm}$.

Esta zona presenta una gran cantidad de terrazas agrícolas abandonadas que, en algunos sectores, se asocian a ojos de agua y riachuelos posiblemente utilizados para irrigarlas. Comparte la vegetación con la base de valle aunque hay una mayor presencia de especies arbustivas y plantas como la thola (Baccharis sp.).

\section{Serranía alta oeste (SAO)}

Está constituida por las partes altas de la formación montañosa que rodea al valle en su parte oeste y se sitúa entre los 3.600 y $3.900 \mathrm{msm}$. La zona se caracteriza por formaciones rocosas calcáreas de color blanquecino y de arenisca roja que le dan un aspecto particular. La vegetación corresponde a un ambiente de puna con abundancia de gramíneas, pajonales, cactáceas pequeñas y thola y la presencia de áreas de bosques relictuales de queñua. Es una zona que aún es usada para el cultivo a secano, especialmente de trigo y cebada, existiendo también terrazas agrícolas abandonadas bajo los bosques de queñua.

\section{Cuencas altas (CA)}

Esta zona rodea al poblado de Palacio Tambo, se define por ser una cuenca en la que confluyen tres ríos que cortan terrazas aluviales a una altitud de 3.200-3.350 msm. Constituye la zona agrícola en esta región y se halla sometida a fuertes vientos durante gran parte del año. Hay una importante presencia de vetas minerales que dan lugar a la existencia de minas, muchas de ellas prehispánicas. En contraste con el valle de San Lucas, la vegetación es escasa, existiendo gramíneas, paja brava, pequeñas cactáceas y algunas plantas espinosas. Al ser una zona poco abrigada la temperatura es menor a la de los valles vecinos.

\section{Serranías altas ( $S A)$}

Rodean a las cuencas altas o altiplanicie con alturas que varían entre 3.350 y $3.500 \mathrm{msm}$. Son zonas no aptas para la agricultura y están relacionadas con actividades mineras y la fundición de metales aprovechando los fuertes vientos que soplan en el lugar. Presentan una escasa vegetación predominando especies como la paja brava.

\section{Metodología}

Para estudiar la región de San Lucas se diseñó una prospección regional sistemática con la finalidad de encontrar y registrar la mayor cantidad de sitios arqueológicos posible. Se definieron dos áreas de estudio, la del valle de San Lucas que abarcó 120 $\mathrm{km}^{2}$ y la de Palacio Tambo con $55 \mathrm{~km}^{2}$. Los límites 
de las áreas de prospección se definieron siguiendo rasgos topográficos y formaciones montañosas que de forma natural delimitan cuencas y valles.

Los sectores de base de valle fueron recorridos intensivamente en las áreas no cultivadas, así como en el piedemonte y las serranías. Las áreas con ocupación humana densa y cultivos cercanos fueron recorridos menos intensivamente. Se siguió la topografía del lugar, salvo en sectores de pendientes empinadas en los que caminar era riesgoso e imposible. El terreno se recorrió con equipos de cuatro a cinco personas separadas en transectos cada 20 a 25 m unos de otros (Rivera Casanovas 2009a). Estos transectos fueron flexibles adaptándose a la topografía irregular del terreno.

Cada sitio hallado fue registrado y georreferenciado, además se realizaron colecciones sistemáticas y diagnósticas de los materiales de superficie. Las colecciones sistemáticas consistieron en círculos de dos metros de diámetro donde se recogieron todos los materiales en superficie. Ninguno de los sitios registrados para el período Arcaico fue excavado, por lo que toda la información proviene del registro de sitios y el análisis de los materiales de superficie.

El estudio de artefactos líticos se basó en un análisis que permitió evaluar los aspectos tecnológicos, morfológicos y funcionales de los materiales observados, una de las principales metas para la identificación inicial de los conjuntos artefactuales a través del tiempo, así como en la elaboración de una tipología de artefactos, especialmente en lo concerniente al período Arcaico en la región.

El análisis se realizó a nivel macroscópico, basándose principalmente en la propuesta tecnomorfológica de Andrefsky (2005) y otros criterios funcionales desarrollados para otras herramientas por investigadores que trabajan en el área andina. Asimismo, se incorporó el análisis de debitage (Andrefsky 1994, 2005) y se tomaron en cuenta criterios morfológicos y funcionales desarrollados por Aschero $(1975,1983)$ en la elaboración de grupos y subgrupos tipológicos para su comparación a nivel regional.

Se desarrolló una clasificación de artefactos en base a los siguientes criterios, en primer lugar se consideró: (1) el tamaño (largo, ancho, espesor), forma y procedencia de la pieza analizada, criterio de identificación de las herramientas analizadas, (2) las materias primas utilizadas en la confección de los artefactos, (3) las técnicas de acabado de los artefactos, en términos de retoque y modificaciones intencionales de los instrumentos, (4) las técnicas de reducción desarrolladas durante la confección de los artefactos, y (5) la funcionalidad e intensidad de uso del artefacto.

\section{Ocupación Arcaica en la Región de San Lucas}

\section{Distribución espacial y microambiental}

En la región de San Lucas se registró un total de 33 sitios pertenecientes al período Arcaico (8.000-2.000/1.500 a.C.), 14 de ellos se encuentran en el valle de San Lucas y 19 en Palacio Tambo (Tabla 1). Si bien los sitios de este período exhiben características similares en cuanto a emplazamiento y materiales, también existen diferencias. A continuación se presentan los datos por zonas así como una comparación entre ambas.

\section{San Lucas}

El tamaño total de la ocupación en la zona del valle de San Lucas durante el período Arcaico es de 2,55 ha, considerando solamente los sitios en que se pudo estimar la extensión de la ocupación. Los asentamientos presentan extensiones menores a una hectárea y se encuentran, en su mayor parte, concentrados en dos agrupamientos claramente discernibles en los sectores norte y sur del valle respectivamente (Figura 4). En algunos casos, los asentamientos se encuentran varios metros

Tabla 1. Distribución microambiental de los sitios Arcaicos en la región de San Lucas. Archaic sites microenvironmental distribution in the San Lucas region.

\begin{tabular}{|c|c|c|c|c|c|c|c|c|c|c|c|}
\hline \multirow{2}{*}{ Tamaño } & \multicolumn{6}{|c|}{ Valle } & \multicolumn{3}{|c|}{ Altiplano } & \multicolumn{2}{|c|}{ Total } \\
\hline & BV & PE & $\mathrm{PO}$ & SAO & CQ & $\%$ & $\mathrm{CA}$ & SA & $\%$ & & $\%$ \\
\hline$>1$ ha & 12 & 2 & & & & & 17 & & & & \\
\hline$<1$ ha & & & & & & & 2 & & & & \\
\hline Total & 12 & 2 & & & & 42,4 & 19 & & 57,6 & 33 & 100 \\
\hline
\end{tabular}




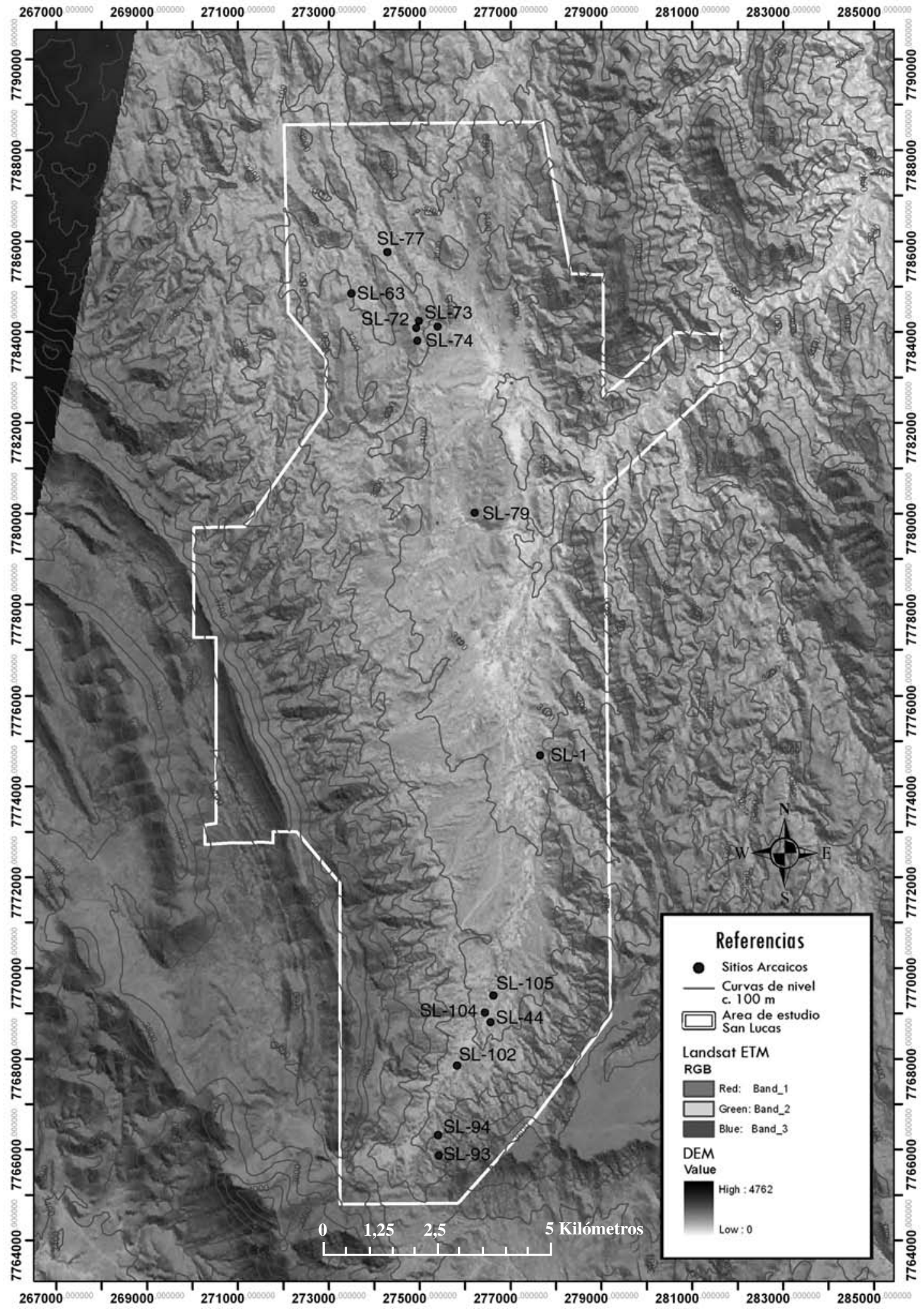

Figura 4. Distribución de sitios del período Arcaico en el valle de San Lucas. Archaic Period site distribution in the San Lucas Valley. 


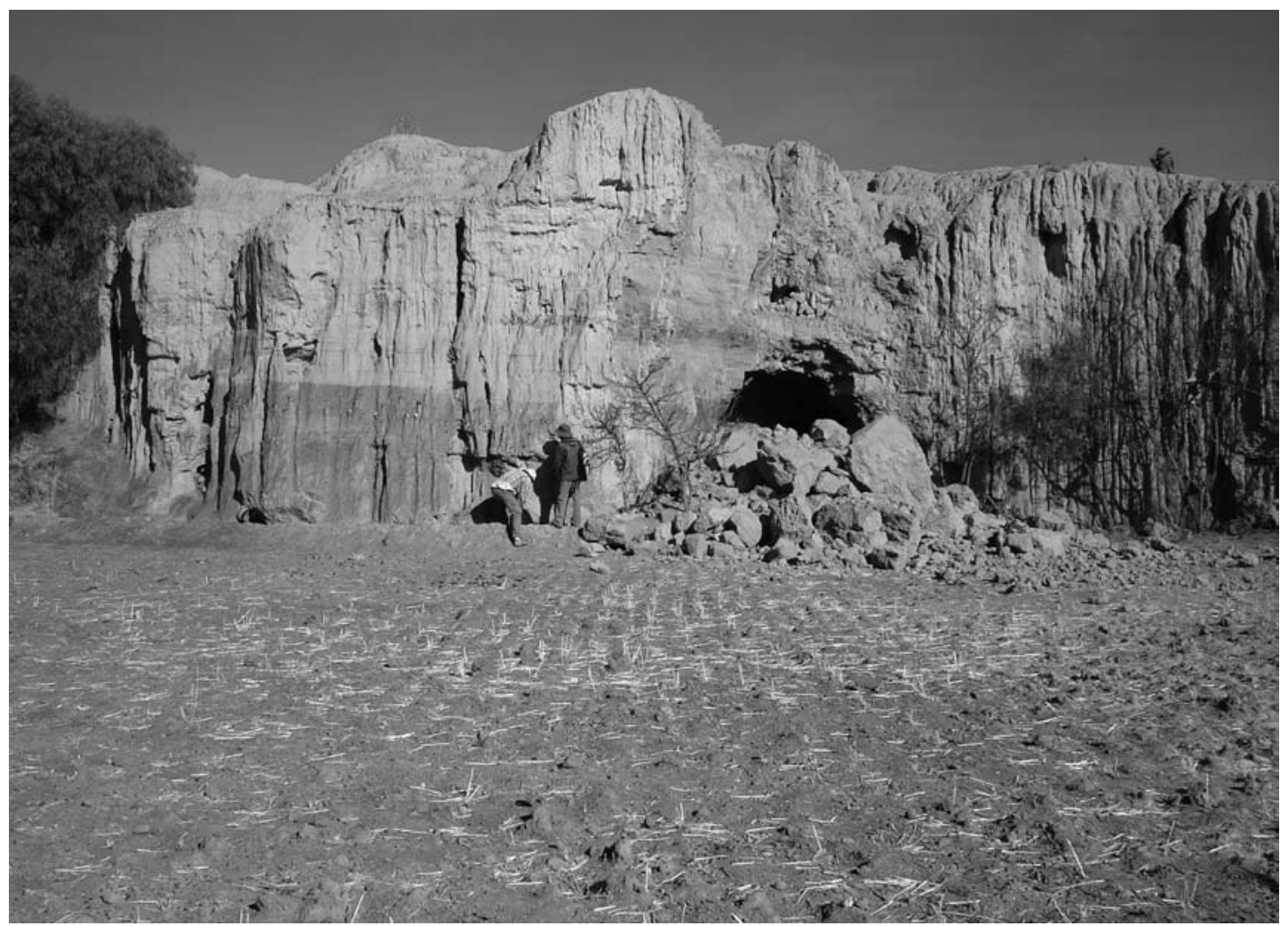

Figura 5. Perfil estratigráfico del sitio SL79, valle de San Lucas. SL79 stratigraphic site profile, San Lucas Valley.

por debajo la superficie actual, como en el caso de SL79, y en otros el material está expuesto por erosión en las terrazas.

Los sitios en San Lucas presentan una distribución asociada al acceso a ciertos recursos disponibles localmente. De ellos $86 \%$ se encuentran emplazados en el microambiente de BV y $14 \%$ en el microambiente de SE. La preferencia por este microambiente se debería a las características geográficas del valle que dan lugar a la presencia de varios ríos permanentes, afluentes del San Lucas, río principal de la zona. La disponibilidad de agua habría permitido asentamientos estacionales o semipermanentes de grupos humanos y facilitado el acceso a una serie de animales que frecuentaban la zona en busca de agua y alimento. Como se mencionó, camélidos y cérvidos habrían habitado la región y pudieron ser las presas predilectas de los grupos humanos en el pasado, sin dejar de lado animales más pequeños como las vizcachas.

Algunos de los sitios arcaicos en el valle de San Lucas presentan evidencias de ocupaciones residenciales como los sitios SL44 y SL79. En el primer sitio (SL44) se identificaron en superficie, en un área erosionada, artefactos líticos y huesos fragmentados asociados a hileras de piedra que pudieron formar parte de algún tipo de estructura. El segundo (SL79) es un sitio identificado por dos

Tabla 2. Fechado AMS obtenido en el sitio SL79. AMS dating from SL79 site.

\begin{tabular}{ccccccccc}
\hline \multirow{2}{*}{ Sitio } & $\begin{array}{c}\mathrm{N}^{\mathbf{2}} \\
\text { laboratorio }\end{array}$ & $\begin{array}{c}\mathrm{N}^{\mathbf{o}} \mathrm{de} \\
\text { muestra }\end{array}$ & Tipo & $\begin{array}{c}\text { Fecha AMS } \\
\text { a.p. }\end{array}$ & 1 Sigma & Cal a.C. & 2 Sigma & Cal a.C. \\
\hline \multirow{2}{*}{ SL79 } & OZK824 & SL79-1 & Carbón & $7.041+/-60$ & 68,3 & $5.976-5.949$ & 95,4 & $5.988-5.739$ \\
& & & & & & $5.919-5.796$ & & \\
\hline
\end{tabular}

Ref. calibración McCormac et al. 2004. 
estratos que contienen ceniza, carbón, huesos de animales y artefactos líticos. El estrato más antiguo se halla seis metros por debajo de la superficie actual (Figura 5). Una muestra de carbón tomada de este fue fechada en 5.988-5.739 a.C. (Tabla 2) correspondiendo al Arcaico Medio.

Estas evidencias sugieren que el valle proporcionaba condiciones favorables para el asentamiento estacional y semiestacional de poblaciones de cazadores y recolectores. Como se mencionó, la disponibilidad permanente de agua, las condiciones climáticas más favorables debido a las diferencias altitudinales con las regiones más altas circundantes, así como una probable vegetación boscosa que proporcionaba frutos y atraía animales habrían hecho la región atractiva para el asentamiento.

\section{Palacio Tambo}

El área de ocupación en Palacio Tambo durante el período Arcaico es de 5,52 ha. Los asentamientos tienen características distintas a las del valle, encontrándose una mayor cantidad de sitios con extensiones mayores (Figura 6). Un 89\% de los sitios tiene extensiones menores a una hectárea, mientras que el $11 \%$ presenta tamaños mayores a una hectárea. Los asentamientos más grandes son los sitios PT37, con una extensión de 1,44 ha, y PT8 con 1,05 ha. El resto de los sitios presenta dimensiones menores, entre 0,64 y 0,001 ha (Tabla 1). Los sitios se encuentran concentrados principalmente siguiendo los cursos de quebradas y cerca de los ríos principales en los sectores norte y este de la zona. En el sector suroeste existe una menor cantidad de sitios, localizados sobre pequeñas colinas y cercanos a los cursos de agua principales del área de estudio.

En el área de Palacio Tambo la localización del polígono de prospección (Figura 2) probablemente crea un sesgo en la distribución microambiental de los sitios. Este se encuentra asociado sólo al microambiente de CA, sin embargo es posible que existan sitios en otros microambientes en la zona (Figura 7). Como se mencionó, una característica de los sitios de la altiplanicie es que son más extensos que los sitios del valle. Es probable que estos sitios hayan sido frecuentemente visitados a través del tiempo y que funcionaran como campamentos base, cercanos a los cursos de agua. En ellos se habrían realizado actividades de preparación y consumo de alimentos, así como tareas de tallado de artefactos líticos. La cantidad de artefactos formales como puntas de proyectil y raspadores, además de la cantidad de desecho de talla apoyan esta idea. Por otra parte, estos datos muestran una diferencia con los conjuntos líticos del valle de San Lucas que no presentan tantas herramientas y desecho de talla.

La preferencia para establecer asentamientos en la zona altiplánica pudo estar relacionada también a los recursos disponibles en la zona para la economía de subsistencia de las poblaciones arcaicas. Aquí probablemente se encontraba una mejor caza por la presencia de espacios abiertos y posibles pastizales. Grupos de cérvidos y camélidos pudieron ser explotados estacionalmente y complementar la dieta de las poblaciones del valle.

\section{Comparación entre zonas prospectadas}

La comparación de los datos obtenidos en las dos zonas prospectadas sugiere que existe una mayor concentración de sitios Arcaicos en la región altiplánica de Palacio Tambo y una menor cantidad de estos en las serranías y base del valle de San Lucas, conformando más del $50 \%$ del total de los sitios encontrados en toda la región (Tabla 1).

El tamaño de los sitios de San Lucas es menor comparado con los de la zona de Palacio Tambo. En San Lucas las extensiones de los sitios no sobrepasan una hectárea mientras que en Palacio Tambo existen sitios con dimensiones mayores a una hectárea.

Los sitios en ambas zonas presentan ciertas características similares en cuanto a su emplazamiento. Tanto los sitios del valle como los de la zona altiplánica se encuentran muy cercanos a fuentes de agua y están situados sobre terrazas aluviales cuaternarias y colinas. Según su distribución microambiental, los sitios del valle se hallan mayormente en el microambiente de base del valle y piedemonte este, mientras que en Palacio Tambo se encuentran sólo en la zona de cuencas altas. Todos estos microambientes son zonas muy productivas para la captación de recursos animales y vegetales.

\section{Aprovechamiento de recursos líticos y movilidad}

El área de estudio se encuentra en la faja subandina del sur que presenta una serie de formaciones geológicas ventajosas para la obtención de rocas de 


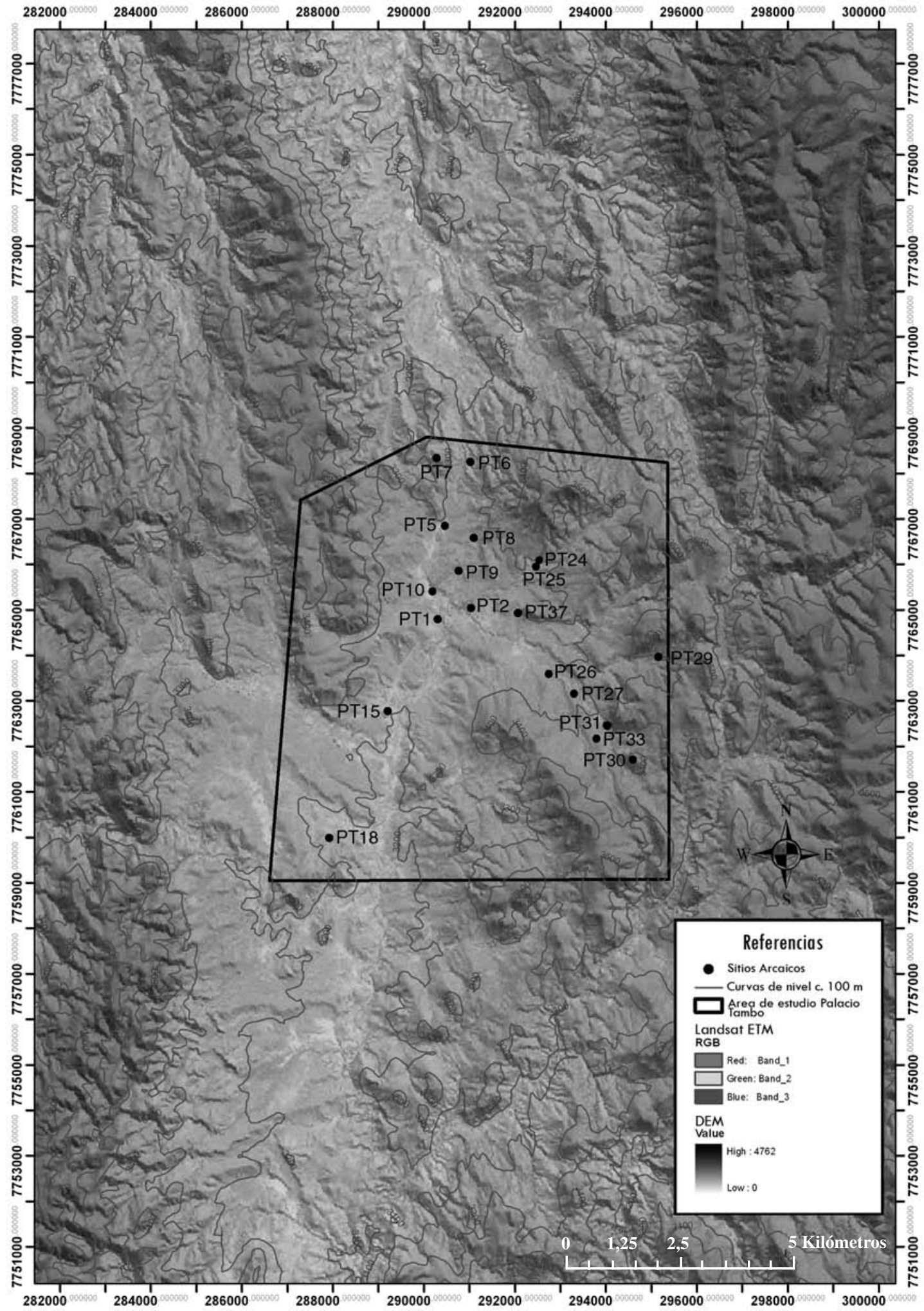

Figura 6. Distribución de sitios arcaicos en la zona de Palacio Tambo. Archaic Period site distribution in the Palacio Tambo zone. 


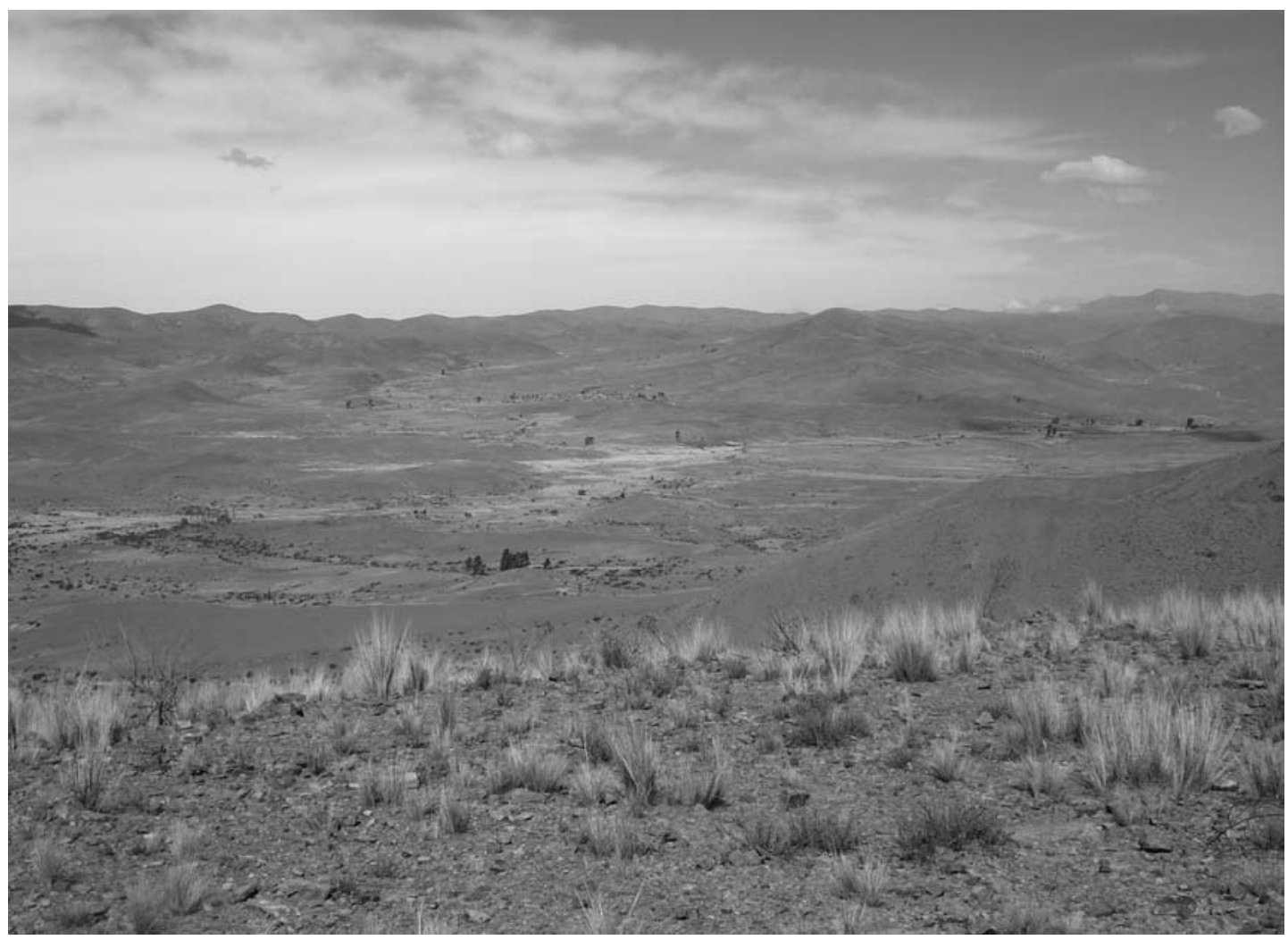

Figura 7. Microambiente de Cuenca Alta en Palacio Tambo.

Upper Basin microenvironment in Palacio Tambo.

distinta naturaleza y calidad. Las materias primas utilizadas en los conjuntos líticos fueron rocas de procuramiento no inmediato en el valle de San Lucas, mientras que en Palacio Tambo fueron de procuramiento inmediato. Preferentemente se manipuló materia prima regional y después la local, basalto y cuarcita respectivamente, presentes en formaciones geológicas de la región a distancias cercanas y relativamente cortas (Troëng et al. 1996). Otras variedades de materiales que se presentan en menor proporción en los conjuntos analizados son sílex, pedernal, calcedonia y cuarzo lechoso. Estos materiales sirvieron de soporte para la confección de herramientas en lascas y láminas (raederas y raspadores en diversas formas y características de retoque, cuchillos y buriles), y una serie de bifaces, como ser puntas de proyectil de diversa morfología, hachas de mano y otros artefactos.

Curiosamente, pese a su disponibilidad inmediata, la cuarcita es la materia prima de menor difusión en el registro arqueológico de la región, especialmente en el valle de San Lucas donde existe una inmensa cantera. La cuarcita fue menos requerida para la confección de distintas herramientas durante el período Arcaico. La reducida explotación de las cuarcitas contrasta con el elevado uso del basalto en los conjuntos líticos analizados.

En el caso del basalto los circuitos de movilidad para la obtención de esta materia prima plantean una dinámica de movimiento más amplia, ya que su obtención implica distancias relativamente más largas a recorrer, sobre todo para los grupos del valle de San Lucas. Las fuentes de basalto identificadas en la región se hallan a distancias de entre 15 a 20 $\mathrm{km}$ dentro del área de estudio y de 40 a $100 \mathrm{~km}$ fuera de esta. Las principales vetas de aprovisionamiento se encuentran en cuatro sectores al sur y este de la región. La fuente más cercana está en la zona de Palacio Tambo, donde el basalto se presenta en el lecho de los ríos en forma de cantos rodados. Los grupos del valle de San Lucas debieron recorrer entre 15 y $20 \mathrm{~km}$ para acceder a esta materia prima, mientras que los de Palacio Tambo la tuvieron próxima.

La segunda veta está en la zona de Chiñimayu, donde existen fuentes de basalto del período 
Cretácico. Esta se encuentra aproximadamente a $39 \mathrm{~km}$ de los sitios ubicados en el sector norte del valle de San Lucas y entre 14 y $17 \mathrm{~km}$ de los sitios ubicados en Palacio Tambo. Otras canteras de basalto más lejanas se ubican al sureste de la región en la zona de Caraparí en los cerros Corral Blanco y Algodonal, donde se han reconocido vetas del período Triásico. La distancia de Cerro Algodonal hasta los sitios del valle es de aproximadamente $110 \mathrm{~km}$ y de $95 \mathrm{~km}$ hasta los sitios ubicados en la zona de Palacio Tambo. La distancia desde el cerro Corral Blanco al valle es de aproximadamente 103 $\mathrm{km}$ y hasta los sitios ubicados en Palacio Tambo de $75 \mathrm{~km}$. Aún no se han realizado análisis de difracción de rayos $\mathrm{X}$ de las muestras para poder obtener la locación más precisa de las fuentes de basalto utilizadas en el pasado.

Esta característica contrasta con los datos de otros sitios de este período en los que se opta por mecanismos de aprovisionamiento inmediato. Existe una preferencia por el basalto para la confección de puntas de proyectil tal vez por ciertas características técnicas o por un sentido de diferenciación social entre grupos y/o individuos. El acceso a las fuentes de basalto situadas al sureste de la región se habría hecho siguiendo los cursos de ríos mayores que conducen hacia el río Pilcomayo y las regiones del Chaco. Estos circuitos también pudieron tener implicancias mayores en la interacción regional y en el contacto con grupos del piedemonte chaqueño.

\section{Conjuntos líticos}

Actualmente los conjuntos líticos se encuentran en fase de análisis, sin embargo se pueden señalar las características de los mismos en base a los resultados preliminares. No se registraron muchos núcleos pero sí una importante cantidad de desecho de talla, sobre todo en los sitios de Palacio Tambo. El proceso de manufactura estuvo orientado hacia la producción de herramientas bifaciales, especialmente preformas para la manufactura de puntas de proyectil sin pedúnculo, tipos con pedúnculo y otras bifaces como raspadores bifaciales y hachas de mano. Al igual que la elaboración de bifaces, la obtención de otros productos de talla estuvo dirigida a la producción de una variedad de herramientas, puntas de proyectil, raspadores, raederas y buriles.

La formalización de los instrumentos fue realizada mediante retoque y microrretoque. $\mathrm{La}$ técnica de microrretoque en los proyectiles es mayormente denticulada y normal en el filo de la hoja. Mientras que para instrumentos elaborados en lascas y láminas, raspadores laterales, terminales, semilunares, ojivales y elípticos (Figura 8), los retoques son principalmente cóncavos y en algunos casos en combinaciones de muesca-cóncavo, los bordes activos de los raspadores laterales son principalmente inversos, directos y alternados. Como se ha mencionado, se prefirió materiales de alta calidad como el basalto para la confección de las herramientas, especialmente para poder producir puntas de proyectil con mayor énfasis en el retocado por presión de sus filos. De esta forma se obtenía el denticulado característico de una serie de puntas de proyectil en la región.

\section{Puntas de proyectil sin pedúnculo}

Uno de los tipos más difundidos en la región es el de puntas triangulares alargadas con base semiconvexa. Estas puntas presentan tamaños de entre seis a ocho centímetros (Figura 8a), son delgadas a medianamente espesas y se caracterizan por su filo denticulado, regular y simétrico. Una variedad de ellas presenta dimensiones menores en cuanto al largo y son mucho más anchas (Figura 8d), en ambos casos el filo de la hoja es denticulado.

Otra variedad menos difundida es la de puntas de proyectil de lados rectos y retoque denticulado (Figura 8b). Al parecer estas puntas tenían dimensiones mayores y se utilizó mayormente la cuarcita para su manufactura, probablemente el rango de las dimensiones de estos proyectiles está entre los 10 y $12 \mathrm{~cm}$. Estas piezas son muy similares en su confección a las de la cercana región de Sama en Tarija.

Un tipo bastante extendido en la región es el de puntas ojivales con tamaños de ocho a $10 \mathrm{~cm}$ de largo, delgadas a medianamente espesas (Figura 8g-k). Estas puntas presentan dos subtipos, uno con pequeños apéndices en el extremo (Figura 8g) y piezas sin esta característica (Figura 8h), por lo general el retoque en estas puntas es cóncavo. Otra variedad es la de puntas ojivales de menores dimensiones, de la cual se han identificado dos variedades: delgadas y anchas. Las primeras tienen entre cuatro a cinco centímetros de largo, son medianamente espesas, con retoque denticulado en el filo y base recta (Figura 8i-j). Las segundas son más anchas, presentan tamaños entre cuatro y cinco centímetros de largo y son el doble de ancho que las anteriores, 


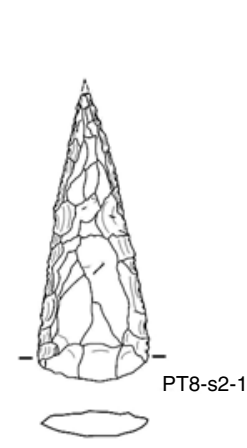

a

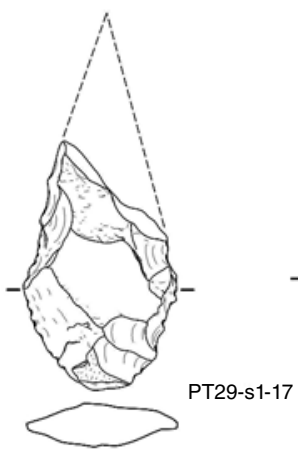

g

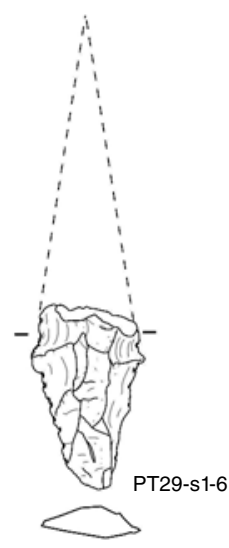

I

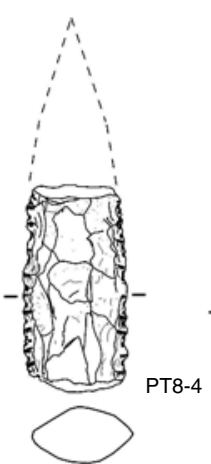

b

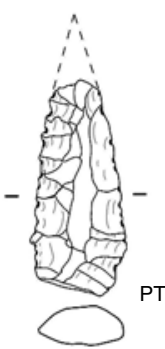

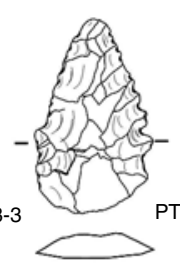

d

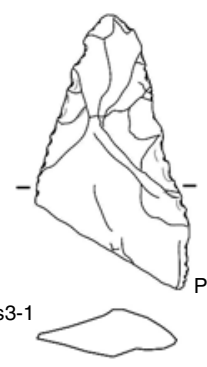

e

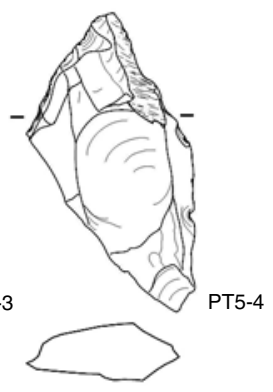

f

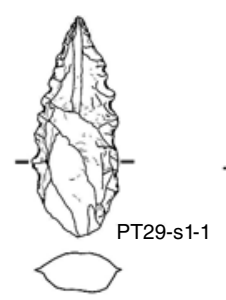

i

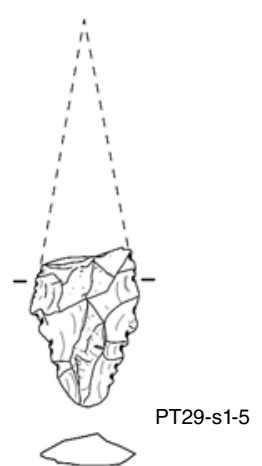

m

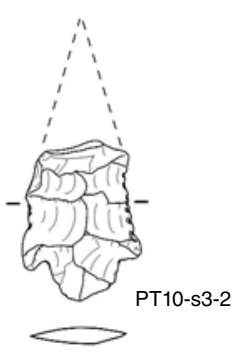

$\mathrm{n}$

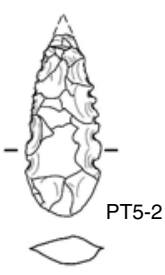

j

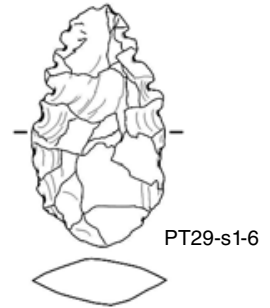

$\mathrm{k}$

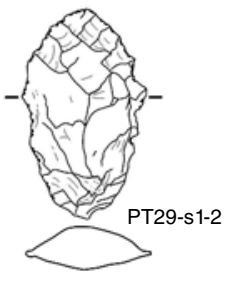

o

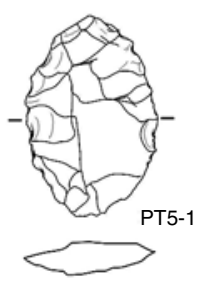

$\mathrm{p}$

Figura 8. Tipología de herramientas bifaciales.

Bifacial tool typology.

entre dos y tres centímetros, y se caracterizan por un retoque denticulado más profundo en el filo (Figura 8k).

También parte del conjunto analizado es la variedad de puntas con truncamiento en la base, con tamaños que van de cinco a siete centímetros y mucho más ancho que todos los tipos reconocidos en la zona. Se identificaron dos subtipos: uno con lados rectos (Figura 8e) y otro con lados semiconvexos (Figura 8f).

Finalmente, otro tipo poco frecuente en la colección es el de puntas elipsoides denticuladas. 
Tienen tamaños entre cuatro y cinco centímetros, presentan espesores medianos y retoque denticulado (Figura 8o).

\section{Comparaciones regionales}

Tanto las puntas triangulares con base semiconvexa como las ojivales han sido identificadas en varios contextos sudamericanos entre el 8.000 al 3.000 a.C. Las primeras han sido descritas por Cardich para el Horizonte II de Lauricocha (Cardich 2006:53) y se encuentran también en el valle de Cinti. En cuanto a las formas ojivales medianas y grandes presentan un mayor espectro geográfico, puntas similares son descritas en varios estudios en Bolivia, Perú y Argentina (Cardich 2006; Ibarra Grasso y Querejazu Lewis 1986; Klink y Aldenderfer 2005; Martínez 2003; Michel López et al. 2000; Núñez et al. 2005; Rick 1980).

En lo referente a las puntas foliáceas anchas, estas han sido reportadas para el sitio de Tulán por Núñez et al. (2005:189) y para el sitio de Quebrada Seca 3, donde se observan ejemplares con las mismas características que los de la región de Antofagasta de la Sierra (Martínez 2003). Con respecto a las puntas elipsoides denticuladas, estas son descritas por Ibarra y Querejazu (1986:112) como hojas de laurel para el sitio de Viscachani, mencionando su parecido a las puntas Sandía. Una punta similar es representada para el sitio de Puripica 3, fechada entre el 8.000-6.000 a.C. (Núñez et al. 2005:208). Finalmente, en cuanto al grupo de puntas con truncamiento, han sido también reconocidas en otras regiones, por ejemplo Cardich presenta este tipo de formas para puntas de lanza en Lauricocha (Cardich 2006:201).

\section{Puntas de proyectil con pedúnculo}

Una de las características de las zonas altas ha sido la variabilidad artefactual, expresada en puntas de proyectil con pedúnculo. Palacio Tambo presenta tipos muy particulares que por el momento indican su aparición exclusiva en la zona. Uno de los tipos menos difundidos en la región es el de puntas de proyectil triangulares, de tamaño mediano a grande, con pedúnculo y apéndices en los extremos (Figura 81-m). Estas puntas son delgadas, de perfil romboidal y al parecer tenían dimensiones entre los 10 y $12 \mathrm{~cm}$. Estos artefactos aparecen sólo en el sitio PT29. Una segunda variedad es la de puntas de
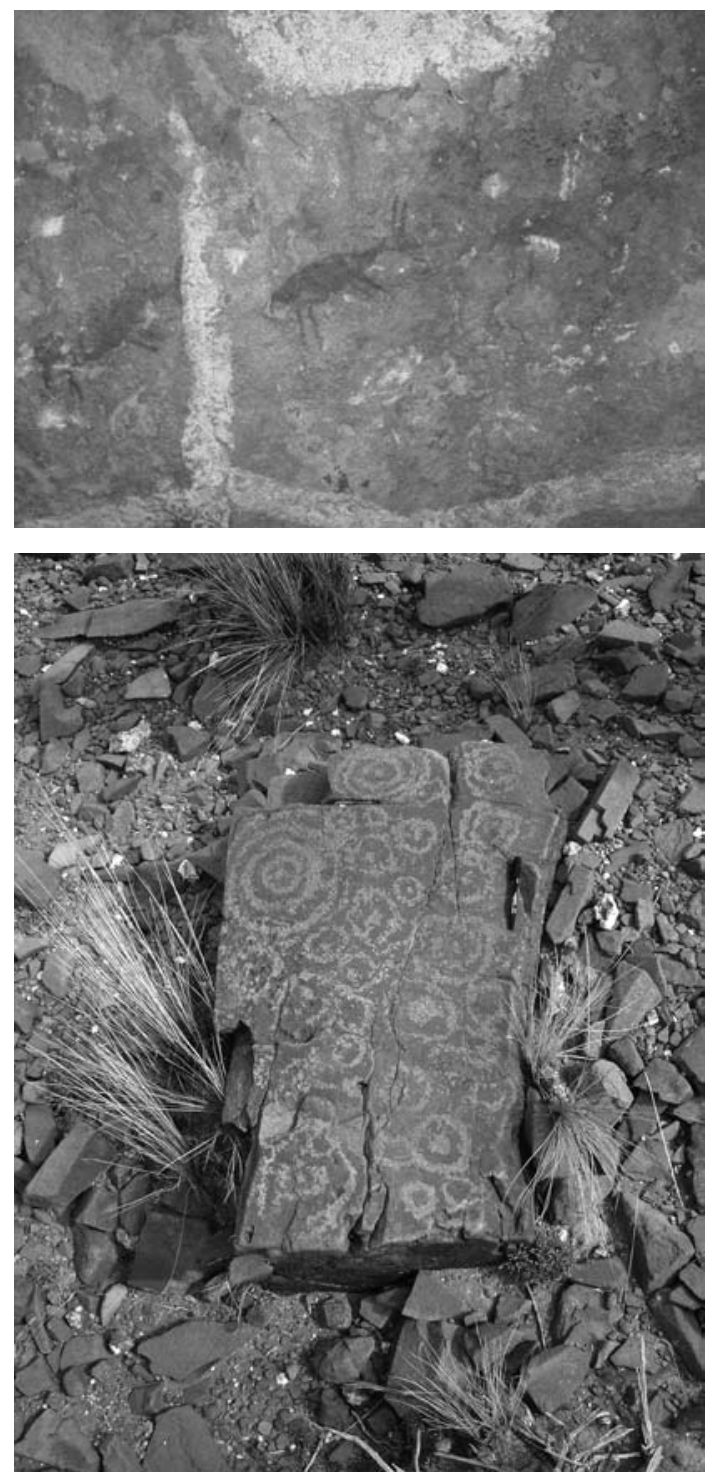

Figura 9. Arte rupestre en el valle de Cinti, cortesía Factum X S.R.L. (9a) y la región de San Lucas (9b).

Rock art in the Cinti Valley, courtesy Factum X S.R.L., (9a), and the San Lucas region (9b).

proyectil con pedúnculo ancho, de perfil delgado y aletas en los extremos de la hoja (Figura 8n). Este tipo de puntas tampoco son muy comunes en la región y sólo aparecen en el sitio PT10.

\section{Comparaciones regionales}

Las puntas con pedúnculo de los tipos 1-m resultan más difíciles de comparar, sin embargo han sido registradas tanto en Bolivia como en Chile asociadas a sitios del Arcaico Temprano. 
Núñez et al. (2005:169, Fig. 62-63) registran este tipo de artefactos en los sitios Ascotán 4 y Ascotán 5, en la zona del Alto Loa. Mientras que en Bolivia, este tipo aparece en las puntas encontradas en la región de Sama (Michel López et al. 2000). En cuanto al tipo n, puntas similares han sido descritas para el sitio de Quebrada Seca 3 y datadas en el 4.900 a.p. en la región de Antofagasta de la Sierra (Hocsman 2006:55). Puntas análogas también son descritas para el Arcaico Tardío por Michel López et al. (2000:23) para la región de Sama.

\section{Arte rupestre}

Existen una variedad de manifestaciones rupestres producidas por grupos tempranos de cazadores recolectores en los valles del sur de Bolivia (Figura 9). En el valle de Cinti, $50 \mathrm{~km}$ al sur del valle de San Lucas, donde existen cuevas y abrigos rocosos, se han identificado sitios con pinturas de camélidos y cérvidos en tonos rojizos. Las características del diseño de estos animales sugieren que pertenecen al Arcaico. Son similares a aquellas representaciones de grupos o filas de camélidos en movimiento descritas para Betanzos (Strecker 2004), así como a las de otros sitios en los Andes centro sur (p.ej., Klarich y Aldenderfer 2001; Schobinger 1988).

En el caso del valle de San Lucas, no se identificaron pinturas pero sí una asociación de sitios arcaicos a afloramientos rocosos con petroglifos. Por ejemplo, el agrupamiento de sitios SL71, 72, 73 y 74 está en estrecha relación con afloramientos de arenisca sobre los cuales se grabaron una serie de motivos geométricos. Estos motivos son círculos, círculos con un punto central, composiciones más intrincadas de círculos, series de líneas paralelas así como otras representaciones geométricas lineales. Es probable que este tipo de motivos tenga una data temprana en los valles del sur, también se los encuentra con profusión en sitios de la región de Betanzos y Tarija.

\section{Consideraciones Finales}

Los datos aquí presentados muestran cómo estudios regionales pueden brindar importantes pautas para entender los procesos de ocupación y poblamiento temprano en los valles del sur de Bolivia. En particular, los trabajos de prospección regional efectuados en la región de San Lucas, Chuquisaca, permitieron identificar 33 sitios pertenecientes al período Arcaico (8.000-2.000/1.500 a.C.), correspondiendo al Arcaico Medio y Tardío.

Estos grupos tuvieron preferencia para ocupar terrazas aluviales en las márgenes de los ríos más importantes donde establecieron campamentos y desarrollaron una serie de actividades. Explotaron una diversidad de recursos de caza como camélidos y cérvidos y probablemente de recolección de frutos silvestres en el valle y la altiplanicie tales como frutos de algarrobo y de cactus.

Tuvieron también circuitos de movilidad que implicaron distintas escalas de movimiento regionales y macrorregionales. La obtención de materias primas como el basalto probablemente incluyó movimientos regionales a distancias relativamente cortas y otras más distantes. Es probable también que se dieran movimientos estacionales entre el valle y la altiplanicie para un eficaz aprovechamiento de los recursos de caza y recolección en relación a las estaciones húmeda y seca. Es posible que en el verano se privilegiara la altiplanicie y en el invierno el valle por su clima más benigno. Sin embargo, existe también la posibilidad de que ambas zonas hayan sido pobladas por grupos distintos.

La distribución de sitios arcaicos en el valle de San Lucas corresponde de manera general a los agrupamientos de sitios que luego se irán desarrollando de manera más notoria en distintos sectores del valle, desde el período Formativo en adelante. En particular, esto se hace evidente en Quirpini (agrupamiento sur) y Querquewisi (agrupamiento norte) con una mayor concentración de sitios. Estos datos sugieren que los grupos tempranos escogieron estos nichos para asentarse seguramente por una disponibilidad de recursos y condiciones óptimas, condiciones que debieron mantenerse en períodos más tardíos. Varios sitios arcaicos en la región muestran una continuidad de ocupación con el período Formativo, sugiriendo cierta continuidad en los patrones de asentamiento y probablemente en sus actividades asociadas.

Un primer acercamiento a los conjuntos artefactuales registrados en San Lucas y Palacio Tambo muestra muchas similitudes con los artefactos encontrados en zonas cercanas como los valles de Cinti y la altiplanicie de Sama, así como con áreas más distantes como la región de la puna de Atacama entre el norte de Chile y noroeste de Argentina. Estas comparaciones nos proporcionan un marco cronológico relativo y preliminar para la ocupación 
arcaica en la región que es también apoyado con el fechado obtenido en los contextos de San Lucas. Sin embargo, este marco deberá ser validado en el futuro con excavaciones y una mayor cantidad de fechados absolutos.

Este trabajo constituye una primera aproximación al estudio de las sociedades tempranas de la región de San Lucas. En la actualidad las investigaciones en la región continúan y esperamos contar en el futuro con información contextual más detallada.

Agradecimientos: Agradecemos a Mark Aldenderfer y Luis Flores Blanco por la invitación para participar en esta publicación, así como a dos revisores anónimos por sus aportes a la claridad del manuscrito. Los trabajos arqueológicos en la región de San Lucas fueron realizados gracias al apoyo de la Heinz Foundation, la cooperación sueca ASDI SAREC a través del Proyecto Autodefinición Cultural del Instituto de Investigaciones Antropológicas y Arqueológicas de la Universidad Mayor de San Andrés, y el Instituto Francés de Estudios Andinos.

También agradecemos el apoyo de la Unidad Nacional de Arqueología, el Municipio de San Lucas, así como de las comunidades y ayllus de la región. A todas las personas que participaron en el equipo de investigación en las distintas fases, así como a los pobladores locales sin cuyo apoyo esta investigación no habría sido posible.

\section{Referencias Citadas}

Abbott, M.B., G.O. Seltzer, K.R. Kelts y J. Southon 1997. Holocene paleohydrology of the Tropical Andes from lake records. Quaternary Research 47:70-80.

Abbott, M.B., B. Wolfe, P. Wolfe, G.O. Seltzer, R. Aravena, B.G. Mark, P.J. Polissar, D.T. Rodbell, H.D. Rowe y M. Vuille 2003. Holocene paleohydrology and glacial history of the Central Andes using multiproxy lake sediment studies. Palaeogeography, Palaeoclimatology, Paleoecology 194:123-138.

Ahlfeld, F. y G. Braniça 1960. Geología de Bolivia. Editorial Don Bosco, La Paz.

Albarracin-Jordan, J. 1996. Tiwanaku: Arqueología Regional y Dinámica Segmentaria. Plural Editores, La Paz.

Albarracin-Jordan, J. y M. Michel López 1998. Diagnóstico arqueológico en la región de San Cristóbal, Provincia Nor Lípez, Departamento Potosí: Informe de prospección regional. Informe presentado a la Empresa Minera San Cristóbal S.A. y la Dirección Nacional de Arqueología de Bolivia.

Aldenderfer, M. 1989. The Archaic Period in the south-central Andes. Journal of World Prehistory 3:117-158.

- - - 1998. Montane Foragers. Asana and the South-Central Andean Archaic. University of Iowa Press, Iowa.

Andrefsky, W.J. 1994. Raw material availability and the organization of technology. American Antiquity 59:21-34.

- - - 2005. Lithics. Macroscopic Approaches to Analysis. Cambridge Manuals in Archaeology, Cambridge.

Arellano, J. 1986. Ñuapua un asentamiento paleoindígena en Bolivia. Prehistóricas 1:49-60.

- - - 1992. El desarrollo cultural prehispánico en el Altiplano y valles interandinos de Bolivia. En Prehistoria Sudamericana, Nuevas Perspectivas, editado por B. Meggers, pp. 309-325. Taraxacum, Washington.

- - - 2000. Arqueología de Lipes, Altiplano Sur de Bolivia. Pontificia Universidad Católica del Ecuador, Quito.
Argollo, J. y P. Mourguriat 1995. Los climas cuaternarios de Bolivia. En Climas Cuaternarios de América del Sur, editado por J. Argollo y P. Mourguriat, pp. 135-155. Proyecto PICG281, ORSTOM, Lima.

- - - 2000. Late Quaternary climate history of the Bolivian Altiplano. Quaternary International 72:37-51.

Aschero, C. 1975. Ensayo para una clasificación morfológica de artefactos líticos aplicada a estudios tipológicos comparativos. Informe presentado al CONICET, Buenos Aires.

1983. Ensayo para una clasificación morfológica de artefactos líticos. Apéndices A y B. Cátedra de Ergología y Tecnología, Universidad de Buenos Aires. Manuscrito en posesión del autor.

Baker, P.A., C.A. Rigsby, G.O. Seltzer, S.C. Fritz, T.K. Lowenstein, N.P. Bacher y C. Véliz 2001. Tropical climate changes at millennial and orbital timescales on the Bolivian Altiplano. Nature 409:698-701.

Barfield, L. 1961. Recent discoveries in the Atacama Desert and the Bolivian Altiplano. American Antiquity 27:93-100.

Berberián, E. y J. Arellano 1977. Los cazadores y recolectores tempranos en la región de Lípez (Departamento Potosí). Publicación 28, Instituto Nacional de Arqueología, La Paz.

Binford, M.W., A.L. Kolata, M. Brenner, J.W. Janusek, M.B. Abbott y J. Curtis 1997. Climate variations and the rise and fall of an Andean civilization. Quaternary Research 47:171-186.

Blard, P.H., J. Lavé, K.A. Farley, M. Fornari, N. Jiménez y V. Ramírez 2009. Late local glacial maximum in the Central Altiplano triggered by cold and locally wet conditions during the paleolake Tauca episode (17-15 ka, Heinrich 1). Quaternary Science Reviews 28:3414-3427.

Brockington, D., D. Pereira Herrera, R. Sanzetenea, R. Céspedes y C. Pérez 1986. Excavaciones en Maira Pampa y Conchupata (Proyecto Formativo). Provincia Mizque, Cochabamba, Bolivia. Cuadernos de Investigación, Serie Arqueología 6. INIAM, Universidad Mayor de San Simón, Cochabamba. 
Brockington, D., D. Pereira Herrera, R. Sanzetenea y M.A. Muñoz 1995. Estudios arqueológicos del período Formativo en el sur-este de Cochabamba. Cuadernos de Investigación, Serie Arqueología 8. INIAM, Universidad Mayor de San Simón, Cochabamba.

Cardich, A. 2006. Hacia una Prehistoria de Sudamérica. Culturas Tempranas de los Andes y la Patagonia. CONCYTEC, Lima.

Céspedes Paz, R. 2002. Precerámico en Cochabamba: la Cuenca de Misicuni. Boletín INIAM-MUSEO, Serie Arqueología 28, Cochabamba.

Hocsman, S. 2006. Tecnología lítica en la transición de cazadores recolectores a sociedades agropastoriles en la porción meridional de los Andes Centro Sur. Estudios Atacameños 32:59-73.

Ibarra Grasso, D. 1965. Prehistoria de Bolivia. Editorial Amigos del Libro, La Paz.

- - - 1973. Prehistoria de Bolivia. Editorial Amigos del Libro, La Paz.

Ibarra Grasso, D. y R. Querejazu Lewis 1986. 30.000 Años de Prehistoria en Bolivia. Editorial Los Amigos del Libro, La Paz-Cochabamba.

Irahola, M. 2007. Proyecto arqueológico "Eucaliptus". Chachapuma Revista de Arqueología Boliviana 2:63-64.

Jiménez, V. 2007. Proyecto arqueológico Mauri "PAM”, Charaña. Chachapuma Revista de Arqueología Boliviana 2:62-63.

Klarich, E. y M. Aldenderfer 2001. Arte rupestre de cazadores y pastores en el río Ilave (sur del Perú). Boletín del Museo Chileno de Arte Precolombino 8:47-58.

Klink, C. y M. Aldenderfer 2005. A projectile point chronology for the South-Central Andean highlands. En Advances in Titicaca Basin Archaeology 1, editado por C. Stanish, A. Cohen y M. Aldenderfer, pp. 25-54. Cotsen Institute of Archaeology, Los Angeles.

Kornfield, W.I. 1975. El lugar de Viscachani dentro del Precerámico andino. Jornadas Peruano-Bolivianas del estudio científico del Altiplano Boliviano y del Sur del Perú. Multicopia.

Kull, C., S. Imhof, M. Grosjean, R. Zech y H. Veit 2008. Late Pleistocene glaciation in the Central Andes: Temperature versus humidity control. A case study from the Eastern Bolivian Andes $\left(17^{\circ} \mathrm{S}\right)$ and regional synthesis. Global and Planetary Change 60:148-164.

Lanata, J.L. y L.A. Borrero 1999. The archaeology of huntergatherers in South America: Recent history and new directions. En Archaeology in Latin America, editado por G.G. Politis y B. Alberti, pp. 76-89. Routledge, London and New York.

Lecoq, P. y R. Céspedes 1997. Panorama archéologique des Zones Méridionales de Bolivie (sud-est Potosí). Bulletin del Institut Français d'Etudes Andines 26:21-61.

Lémuz Aguirre, C. y K. Aranda Álvarez 2008. Mapa de áreas arqueológicas potenciales del valle de La Paz. Gobierno Municipal de La Paz, Oficialía Mayor de Culturas, La Paz.

Levenu, A., M. Fornari y M. Sebrier 1984. Existence de Deux Nouveaux Épisodes Lacustres Quaternaries dans L'Altiplano Péru Bolivien. Cahiers ORSTOM.

Lizárraga-Mehringer, Y. 2004. Viscachani y el Precerámico de Bolivia. Tesis Doctoral, Universidad de Colonia, Colonia.
Martínez, J.G. 2003. Ocupaciones Humanas Tempranas y Tecnología de Caza en la Microrregión de Antofagasta de la Sierra (10000-7000 AP). Tesis para optar al grado de Doctor en Arqueología, Facultad de Ciencias Naturales e Instituto Miguel Lillo, Universidad Nacional de Tucumán, Tucumán.

May, J.H., R. Zech y H. Veit 2008. Late Quaternary paleosol sediment sequences and landscape evolution along the Andean Piedmont, Bolivian Chaco. Geomorphology 98:34-54.

McCormac, F.G., A.B. Hogg, P.G. Blackwell, C.E. Buck, T.F.G. Higham y P.J. Reimer 2004. SHCalO4 Southern Hemisphere Calibration 0-11.0 Cal Kyr BP. Radiocarbon 46:1087-1092.

Michel López, M., P. Ayala, D. Gutiérrez, M. Beierlein, S. Calla Maldonado y G. Palacios 2007 [2005]. Los chichas preinkaicos del Sur de Bolivia y Noroeste de la Argentina. Pacarina 4:81-96.

Michel López, M., M. Beierlein de Gutiérrez y D. Gutiérrez 2000. Diagnóstico arqueológico para la Reserva Biológica Cordillera de Sama. Informe final presentado a Prometa, La Paz.

Muñoz Reyes, J. 1980. Geografía de Bolivia. Academia Nacional de Ciencias de Bolivia, La Paz.

Navarro, G. y M. Maldonado 2004. Geografía Ecológica de Bolivia. Vegetación y Ambientes Acuáticos. Fundación Simón I. Patiño, Santa Cruz.

Núñez, L., M. Grosjean e I. Cartajena 2005. Ocupaciones Humanas y Paleoambientes en la Puna de Atacama. Instituto de Investigaciones Arqueológicas y Museo, Universidad Católica del Norte, Taraxacum, San Pedro de Atacama.

Núñez, L. y C. Santoro 1988. Cazadores de la puna seca y salada del área centro sur andina. Estudios Atacameños 9:11-60.

Patterson, T.C. y R.F. Heizer 1965. A Preceramic stone tool collection from Viscachani, Bolivia. Ñawpa Pacha 3:107-115.

Placzek, C., J. Quade y P.J. Patchett 2006. Geochronology and stratigraphy of Late Pleistocene lake cycles on the Southern Bolivian Altiplano: implications for causes of tropical climate change. Geological Society of America Bulletin 118:515-532.

Placzek, C., J. Quade, J.L. Betancourt, P.J. Patchett, J.A. Rech, C. Latorre, A. Matmon, C. Holmgren y N.B. English 2009. Climate in the dry central Andes over geologic, millennial, and interannual timescales. Annals of the Missouri Botanical Garden 96:386-397.

Rick, J. 1980. Prehistoric Hunters of the High Andes. Studies in Archaeology. Academic Press, New York.

- - - 1988. The character and context of Highland Preceramic society. En Peruvian Prehistory, editado por R. Keatinge, pp. 3-40. Cambridge University Press, London.

Rigsby, C., J. Platt Bradbury, P.A. Baker, S.M. Rollins y M.R. Warren 2005. Late Quaternary palaeolakes, rivers, and wetlands on the Bolivian Altiplano and their palaeoclimatic implications. Journal of Quaternary Science 20:671-691.

Rivera Casanovas, C. 2002. Wild Resources in the Andes: Algarrobo, Chañar and Palqui: Implications for Archaeology. Tesis de Maestría, University of Pittsburgh, Pittsburgh.

- - - 2004. Regional Settlement Patterns and Political Complexity in the Cinti Valley, Bolivia. Ph.D. Dissertation, University of Pittsburgh, Pittsburgh. 
- - - 2009a. Proyecto Arqueológico San Lucas: Trayectorias evolutivas locales y sistemas de territorialidad discontinuos prehispánicos y coloniales en San Lucas, Chuquisaca. Informe de avance de investigación presentado a la Unidad Nacional de Arqueología y el Instituto de Investigaciones Antropológicas y Arqueológicas de la UMSA, La Paz.

- - - 2009b. Análisis y diagnóstico sobre recursos arqueológicos. En Análisis arqueológico en Los Cintis. Estudio presentado a la Prefectura del Departamento de Chuquisaca. Consultora FACTUM X, La Paz.

Rivera Casanovas, C., S. Alconini Mujica y M. Michel López 1993. Proyecto Arqueológico Camargo. Prospección arqueológica en Camargo. Informe presentado a SAGIC S.A, La Paz

Rivera Casanovas, C. y S. Calla Maldonado 2011. Proyecto Arqueológico Betanzos. Informe de prospección regional y excavación. Informe presentado a la Sociedad para la Investigación del Arte Rupestre de Bolivia y la Unidad Nacional de Arqueología y Museos, La Paz.

Rivera Casanovas, C., P. Álvarez y S. Calla 2007. Proyecto Arqueológico Vallegrande. Informe temporada de campo 2006. Presentado a la Independent Power Corporation y la Sociedad para la Investigación del Arte Rupestre de Bolivia (SIARB), La Paz.
Schobinger, J. 1988. Prehistoria de Sudamérica. Culturas Precerámicas. Alianza Editorial, Madrid.

Seltzer, G.O. 1992. Late Quaternary glaciation of the Cordillera Real, Bolivia. Journal of Quaternary Science 7:87-98.

Servant, M. y S. Servant-Vildary 2003. Holocene precipitation and atmospheric changes inferred from river paleowetlands in the Bolivian Andes. Palaeogeography, Palaeoclimatology, Palaeoecology 194:187-206.

Stanish, C. 2003. Ancient Titicaca: The Evolution of Complex Society in Southern Peru and Northern Bolivia. University of California Press, Los Angeles.

Strecker, M. 2004. Arte rupestre de Betanzos, Depto. de Potosí, Bolivia. http://rupestreweb.tripod.com/betanzos.html (23 enero 2009).

Troëng, B., C. Riera-Kilibarda y R. Rößling 1996. Mapas temáticos de recursos minerales de Bolivia. Boletín del Servicio Geológico de Bolivia 8. La Paz.

ZONISIG 2000. Zonificación Agroecológica y Socioeconómica Departamento de Chuquisaca. Prefectura del Departamento de Chuquisaca, Universidad de San Francisco Xavier, Ministerio de Desarrollo Sostenible y Planificación, Zonisig-DHV Consultores-ITC, Sucre. 